\title{
Determination of two-photon absorption in nucleobase analogues: a QR-DFT perspective
}

\author{
Thomas Malcomson ${ }^{1}$ (D)
}

Received: 13 August 2021 / Accepted: 27 January 2022 / Published online: 18 February 2022

(c) The Author(s) 2022

\begin{abstract}
With the prevalence of fluorescence spectroscopy in biological systems, and the benefits of two-photon absorption techniques, presented here is an assessment of the two-photon accessibility of modern fluorescent nucleobase analogues utilising quadratic response DFT. Due to the complex environment experienced by these nucleobases, the two-photon spectra of each analogue has been assessed in the presence of both $\pi$-stacked and hydrogen-bonding interactions involving the canonical nucleobases. Findings suggest that the $\pi$-stacking environment provides a more significant effect on the spectra of the analogues studies than a hydrogen-bonding environment; analogue structures presenting high two-photon cross-section values for one or more states coincide with polycyclic extensions to preserved canonical base structure, as observed in the qA family of analogues, while analogue structures more closely resembling the structure of the base in question present a much more muted spectra in comparison. Results from this investigation have also allowed for the derivation of a number of design rules for the development of potential, two-photon specific, analogues for future use in both imaging and potential photochemical activation.
\end{abstract}

\section{Graphical abstract}

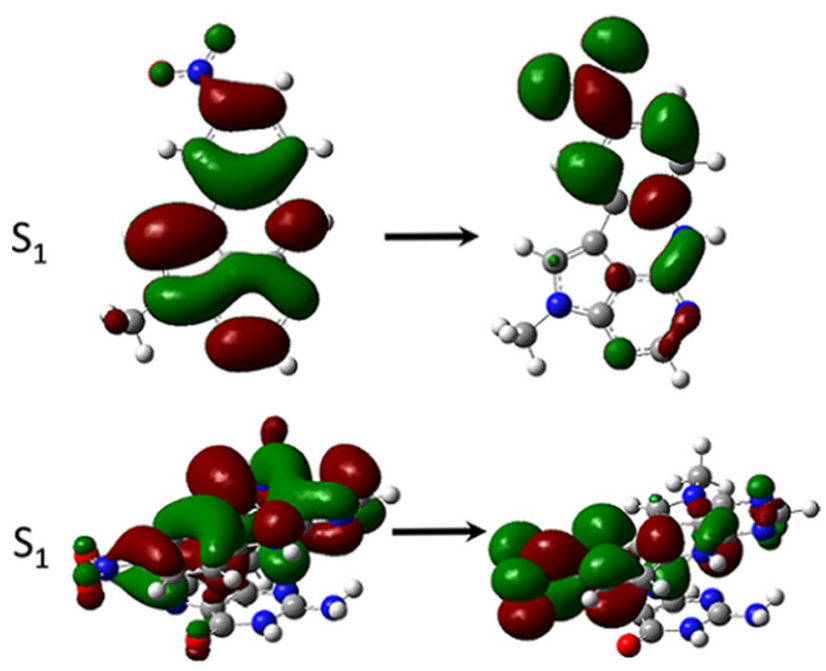

Keywords Nucleobases $\cdot$ QR-DFT $\cdot$ Two-photon absorption $\cdot \pi$-stacking $\cdot$ Two-photon spectroscopy

Thomas Malcomson

thomas.malcomson@manchester.ac.uk

1 Department of Chemistry, School of Natural Sciences, University of Manchester, Oxford Road, Manchester M13 9PL, UK

\section{Introduction}

The environmental fluctuations and reactive alterations experienced by nucleic acids (Fig. 1) are both wide ranging and complex including, but not limited to: base flipping 

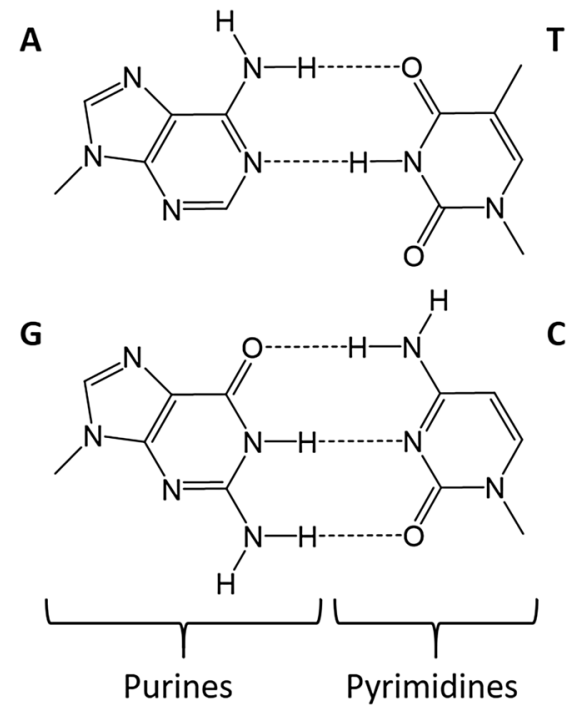

Fig. 1 Schematic structures of Watson-Crick base pairs between canonical bases

[1], methylation [2-6], depurination [7, 8] and depyrimidination [9], and ligand binding [10]. These changes to the local environment occur both in concert with, and independent of, the expected changes experienced throughout the normal function of nucleic acids; namely, the $\pi$-stacking interactions observed upon accumulation into a strand of DNA [11-16], and the hydrogen bonding necessary for combining two strands into the double helix [17-20]. The insights gained from the ability to probe the behaviour of nucleic acids throughout the cell are both wide ranging and of incredible importance.

Due to its sensitivity and straightforward application, fluorescence spectroscopy has remained one of the most used tools for analysis, particularly in biomolecular systems [21-29]. Initially, application of fluorescence spectroscopy centred around the use of dyes, commonly involving cyanine or rhodamine moieties, attached to native nucleosides [30]. While these dyes were effective in visualising the location of bases within the cell, these compounds displayed poor sensitivity to local base-base interactions due to the use of large linkers separating the dye moiety from the base.

The advent of these methodologies, coupled with the lack of dye sensitivity to environmental changes, has created a niche role for environmentally sensitive fluorescent nucleobase analogues (FBAs) to act as powerful tools for the investigation of the structure, dynamics, and environmental properties of nucleic acids [31-33]. The proposed advantage in the design of the analogues over their dye-based predecessors is that, given the lack of mobility provided by the long linker, analogues would have a well-defined geometry relative to the local DNA structure.

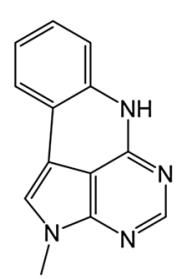

qA<smiles>Cn1cc2c3c(ncnc31)Nc1cc3ccccc3cc1-2</smiles>

pA<smiles>Cc1nc2c(=O)[nH]c(N)nc2n(C)c1=O</smiles><smiles>Cn1cc2c3c(ncnc31)Nc1ccc([N+](=O)[O-])cc1-2</smiles>

qAnitro<smiles>[R][Y4](=O)On1cc([X])c(Nc2ccccc2[X])nc1=O</smiles>
tC; $X=S$<smiles>CN(C)c1ccc2c(c1)c(N)nc(=O)n2C</smiles><smiles></smiles>
6AzaS; $X=S$<smiles>Cc1nc2c(N)ncnc2n(C)c1=O</smiles><smiles>Cn1c(=O)[nH]c(=O)c2cc3c(cc21)OCO3</smiles><smiles>Cn1cnc2cnc(N)nc21</smiles>

Fig. 2 Schematic structures of fluorescent nucleobases base analogues selected for study

The probes created from these analogues (Fig. 2) can be considered to occupy one of a number of categories, ranging from: (i) those closely resembling the native bases they aim to replace to maintain the $\pi$-stacking and hydrogen bonding characteristics, such as 2-amino-purine (2AP) [30, 34]; (ii) molecules employing pteridine moieties [35], as seen with 6-MI [36] and 6MAP [37], which have seen use as highly fluorescent analogues for the purine bases (Fig. 1); (iii) bases which have been extended to include a conjugated, primarily aromatic, moiety such as that observed in $6 \mathrm{AzaO}$ and $6 \mathrm{AzaS}$ [33]; (iv) structures in which fluorescently active aromatic moieties are linked directly to the native base, as observed in the adenine analogues, $\mathbf{p A}$ [38], $\mathbf{q} \mathbf{A}, \mathbf{q A N} \mathbf{A} 1$, and $\mathbf{q A n i t r o}$ [39-41], the cytosine analogues $\mathbf{t C}^{O}$ [42], tC [30,43] and ${ }^{D M A} \mathrm{C}$ [44], as well as the thymine analogue ${ }^{d i o x} \mathbf{T}$ [45].

The sensitivity of base analogues to their environment has been been shown to vary; while $\mathbf{2 A P}$ shows moderate environmental sensitivity [30, 46-51] $\mathbf{t C}$ and $\mathbf{t C}{ }^{O}$ have been shown to be relatively insensitive to their microenvironment [30, 52-54]. Regardless of the degree of environmental sensitivity attributed to a given analogue, the ideal utilisation of these compounds is in the in vivo study of the 
cellular environment. This creates a number of challenges in the successful design of analogues: while many present high quantum yields, they commonly exhibit significantly lower absorption cross sections when compared to dye-based probes; additionally, the absorption of most analogues takes place at higher wavelengths, often in the UV region, which can lead to undesirable photobleaching effects [55-59]; this high energy absorption presents a further challenge in the tissue penetration within biological media, which is particularly poor $[60,61]$.

One method that has been suggested to address these challenges is through the use of multiphoton absorption [62]. Multiphoton absorption enables increased tissue penetration by allowing for a longer wavelength to be used while also reducing photobleaching of out of focus chromophores due to the increased three-dimensional localisation afforded. Additional advantages in the use of multiphoton absorption are: the ability to target excited states and, as such, areas of the excited state spectrum that are not accessible in one-photon absorption, as well as reducing background fluorescence from secondary chromophores and optical components [63].

A number of analogues have previously been investigated experimentally for two-photon viability, including: 2AP [30, 64], 6-MI [64, 65], 6MAP [66], ABN [67], pA [38, 38, 68] and $\mathbf{t C}$ [30]. This paper looks to expand this investigation to a wider range of commonly utilised analogues (Fig. 2), assessing the two-photon profile of the isolated analogues as well as quantifying the environmental sensitivity of each analogue upon formation of: (i) hydrogen-bonded dimers such that Watson-Crick pairs (Fig. 1) are conserved; and ii) $\pi$-stacked dimers with each of the native bases. NonWatson-Crick base pairs and $\pi$-stacked dimers involving more than one analogue have not been accounted for here, nor have the effects of $\pi$-stacked trimers in which an analogue is sandwiched between two native bases; this limitation was selected due to the scaling of the computational methods applied throughout the study. For ease of discussion, throughout this paper a shorthand nomenclature for the dimer structures has been utilised such that the hydrogenbonded dimer between adenine and thymine will be represented as A-T while the $\pi$-stacked dimer will be represented by $\mathbf{A}-\pi$-T. When discussing situations covering more than one of the canonical bases the symbol $\mathbf{B}$ will be used such that $\mathbf{B}-\pi$-2AP represents the $\pi$-stacking interaction of the 2AP analogue and any canonical base.

\section{Theoretical methods}

Geometry optimisations and linear response, or timedependent (TD), DFT calculations for the one-photon spectra, were carried out with the Gaussian09 software package
[69]; orbitals and surfaces where visualised using the GaussView5 interface [70].

Optimisations utilised the $\omega$ B97X-D functional [71], which has been shown to provide strong results for $\pi$-stacking interactions [72-75], along with the cc-pVTZ basis set [76-78]; determination of structural minima was conducted through frequency analysis and noted by the presence of only positive curvature; the use of this model chemistry has been well established for giving appropriate geometry determinations for molecules of this type [79-84]. Geometry selection for hydrogen-bonded dimers was determined so as to mimic the hydrogen-bonded structures of correctly orientated Watson-Crick dimeric pairs.

Geometries corresponding to $\pi$-stacked minima were determined through optimisation from a starting point in which the plane of each base was $3.4 \AA$ apart and the twist of $\pi$-stacked bases, determined by the methylated nitrogen of each base representing the contact point for the phosphate backbone, was set to best approximate the structure of a B-form DNA strand and assuming the formation of a Watson-Crick pair upon hydrogen-bonding, as utilised and recommended in previous research $[85,86]$; geometries where then allowed to relax through optimisation and, again, minima were determined through frequency analysis. Analysis of each structure at the determined minima showed minimal deviation from the $3.4 \AA$ starting point (Table S1), with an average deviation of $0.05 \AA$. Solvent effects for all optimisations were accounted for through use of the PCM solvent model $[87,88]$ to approximate an aqueous environment.

TD-DFT data, for the characterisation of excited state character and determination of orbital contributions, were determined using a range of DFT functionals, namely: CAM-B3LYP [89], B3LYP [90, 90-95], BLYP [90, 93, 95], BP86 [96, 97] and PBE0 [98], each with the Dunning ccpVTZ basis [99]. BLYP values are reported here due to their agreement with the experimental UV-Vis spectra of a range of bases and analogues studied throughout this work [37, 38, $38-42,44,45,53,68,100,101]$ when compared to the other model chemistries tested; average errors for the functionals considered, when compared to the experimentally reported values, in the determination of two-photon energies were found to be: CAM-B3LYP $=0.62 \mathrm{eV}$; B3LYP $=0.29 \mathrm{eV}$; $\mathrm{BLYP}=0.14 \mathrm{eV}$. Examples of functional performance are observed in Fig. 3 showing that, while the B3LYP functional does particularly well at determining the absorption of the pA analogue (error $=0.15 \mathrm{eV}$ ), this is offset by significantly worse performance for other analogues, such as $\mathbf{2 A P}$ (error $=0.32 \mathrm{eV}$ ). While the BP86 and BLYP functionals were found to perform equivalently, BLYP was selected due to its availability for QR-DFT calculations.

The use of the one-photon UV-Vis spectra and determination of two-photon energies for absorption maxima were chosen as the criteria for benchmarking due to the reliability 
Fig. 3 Calibration of the functional selected based on the determination of the one-photon spectra of 2AP (experimental maxima $=310 \mathrm{~nm}[30,46-51])$ and $\mathbf{p A}$ (experimental maxima $=390 \mathrm{~nm}[38,68])$

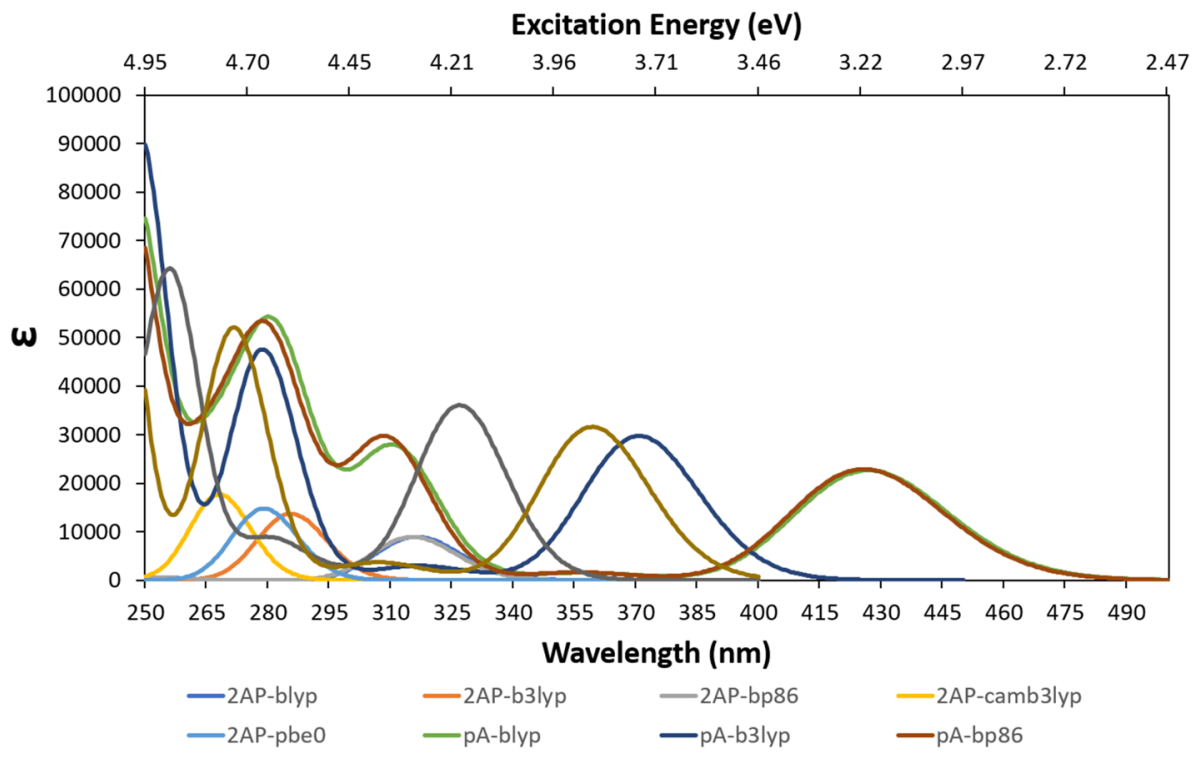

of density functional methods in reproducing these values at a quantitative level, particularly in relation to the excitation energies of the states to be investigated. This is in comparison to attempting to benchmark directly against the experimental two-photon cross section, where QR-DFT values can be commonly found to fall within $\times 8-\times 10$ larger than the experimental values; this is partially due to the inability of the calculations, including only an implicit solvent model, to mimic the complex environment found in in vitro experimentation which commonly result in a significant reduction in photoactivity compared to an isolated molecule. However, while the potential discrepancy in cross-section values should be noted, the model chemistries applied here are still capable of providing significant insight into the excited state behaviour of these compounds and their potential viability for TPA applications through identification of states with promising cross sections.

Direct comparison with experimental TPA cross-section values (Tables 2, 3, and S2) present a consistent over-estimation of the cross-section value, as expected; this overestimation ranges from $\times 2$ to $\times 9$, a larger range of agreement than generally found. Additionally, calculations appear to consistently, and perhaps unsurprisingly, identify a number of areas of predicted high TPA absorption at higher energies than commonly investigated during experiment.

The use of quadratic response (QR) DFT calculations, as utilised here, has been well established in providing high accuracy values for similar systems [102-108]. Additionally, BLYP values were also shown to present good agreement in the identification of TPA high cross-section states when compared to experimental values for 2AP [30, 64], 6MAP [66], 6-MI [64, 65], pA [38, 38, 68], and tC [30].

Solvent effects during QR-DFT calculations were accounted for using the COSMO approximation to model an aqueous environment as implemented through FixSol in Dalton 2020

[109-112]. An excited state threshold of $5.0 \mathrm{eV}(\approx 250$ $\mathrm{nm})$ was applied in the reporting of data to limit the number of states in question to those that could reasonably be accessed in various environments, taking into account issues arising from the lack of tissue penetration for in vivo environments specifically $[60,61]$.

Within the Quadratic Response (QR) formalism, the TPA energies and $\delta^{T P}$ values can be solved for directly through the use of the single residue of the quadratic response function:

$\lim _{\omega_{c} \rightarrow \omega_{f}}\left(\omega_{c}-\omega_{f}\right)\left\langle\left\langle\hat{\mu}_{a} ; \hat{\mu}_{b} \hat{\mu}_{c}\right\rangle\right\rangle_{\omega_{f / 2}, \omega_{i}}=-T_{a b}^{2 \omega_{f} f}\left\langle f\left|\hat{\mu}_{c}\right| 0\right\rangle$.

Utilising an implicit summation over an infinite number of states, the two-photon probabilities $(\delta(\omega))$ can be obtained in the form of single residues such that:

$\lim _{\omega_{c} \rightarrow \omega_{f}}\left(\omega_{c}-\omega_{f}\right)\left\langle\left\langle\mu_{a} ; \mu_{b} \mu_{c}\right\rangle\right\rangle_{-\omega_{b} \omega_{c}}=\delta(\omega)\left\langle f\left|\mu_{c}\right| 0\right\rangle$

in which $\delta(\omega)$ can be expressed as:

$-\sum_{X}\left[\frac{\left\langle 0\left|\mu_{a}\right| X\right\rangle\left\langle X\left|\mu_{b}-\left\langle 0\left|\mu_{b}\right| 0\right\rangle\right| Y\right\rangle}{\left(\omega_{0 X}-\left(\omega_{0 Y}-\omega_{0 b}\right)\right)-i \Gamma_{X 0}}\right.$
$\left.+\frac{\left\langle 0\left|\mu_{b}\right| X\right\rangle\left\langle X\left|\mu_{a}-\left\langle 0\left|\mu_{a}\right| 0\right\rangle\right| Y\right\rangle}{\left(\omega_{0 X}-\omega_{0 b}\right)-i \Gamma_{X 0}}\right]$,

where $\mu_{a}, \mu_{b}$, and $\mu_{c}$ represent the dipole moments produced in response to an electric field of frequency $\omega_{a}, \omega_{b}$, and $\omega_{c}$, respectively. It is these dipole moments that can then be utilised to determine $\delta^{T P}$ values.

Two-photon cross sections $\left(\sigma^{T P}\right)$ are reported here, as defined through QR-DFT implemented in Dalton2020 [109, 110]. Reported values are determined by the equation: 
$\sigma^{T P}=\frac{8 \pi^{3} \alpha^{2} \hbar}{e^{4}} E^{2} \delta^{T P}$,

producing values in a.u, defined as $10^{-50} \mathrm{~cm}^{4} \mathrm{~s}_{\text {photon }}{ }^{-1}$, equating to Goeppert-Mayer units (GM), where:

$E=\frac{\omega}{\Gamma}$,

such that $\omega$ is the photon energy in $\mathrm{eV}$ and $\Gamma$ is a broadening factor of $0.1 \mathrm{eV}$ [113]; while uncertainty in the broadening factor can create an argument of the use of values larger, or smaller, by a factor of 2 , the value chosen here is consistent with previous work $[35,114,115]$ and in the prediction of the two-photon line shape of a number of other molecules $[113,116-119] . \alpha$ is the fine line constant, and the transition strength $\left(\delta^{T P}\right)$ is given by [102]:

$\delta^{T P}=F \delta^{F}+G \delta^{G}+H \delta^{H}$,

in which $F, G$, and $H$ vary depending on the polarisation of light used; under parallel linearly polarised light, $F=G=H=2$. In addition, each component $\left(\delta^{F} / \delta^{G} / \delta^{H}\right)$ takes the form:

$\delta^{F}=\frac{1}{30} \sum_{\alpha, \beta} S_{\alpha \alpha} S_{\beta \beta}$,

$\delta^{G}=\frac{1}{30} \sum_{\alpha, \beta} S_{\alpha \beta} S_{\alpha \beta}$

$\delta^{H}=\frac{1}{30} \sum_{\alpha, \beta} S_{\alpha \beta} S_{\beta \alpha}$

where $\alpha$ and $\beta$ are the components of the dipole operator such that $\alpha, \beta=x, y, z$, and the sums contained within each term run over combinations of these components for the operators acting between the ground $(|0\rangle)$, intermediate $(|i\rangle)$, and final $(|f\rangle)$ states, such that:

$S_{\alpha, \beta}=\sum_{i} \frac{\left\langle 0\left|\mu^{\alpha}\right| i\right\rangle\left\langle i\left|\mu^{\beta}\right| f\right\rangle}{\omega_{i}-\frac{\omega_{f}}{2}}+\frac{\left\langle 0\left|\mu^{\beta}\right| i\right\rangle\left\langle i\left|\mu^{\alpha}\right| f\right\rangle}{\omega_{i}-\frac{\omega_{f}}{2}}$,

where $\omega_{i}$ is the transition frequency to the intermediate (virtual) state, and $\omega_{f}$ is the transition frequency for the final state, i.e., the state in question.

Due to the nature of the denominator in Eq. $10\left(\omega_{i}-\frac{\omega_{f}}{2}\right)$ there emerges the possibility, when the calculation of large numbers of states is required, that artificially enhanced values may be observed when $\omega_{i}-\frac{\omega_{f}}{2} \rightarrow 0$. This effect is most commonly observed when a compound possesses a low lying state (e.g., $S_{1}$ ) at close to half the excitation energy of a higher lying state; this can be seen when considering the T-qAnitro dimer (Table S6) in which the $S_{1}$ and $S_{2}$ states $(1.94 \mathrm{eV}$ and $2.27 \mathrm{eV})$ present high resonance with states $S_{16}$ and $S_{28}$ (3.94 and $4.53 \mathrm{eV}$, respectively). While the presence of this artificial enhancement does result in a reduction of the quantitative accuracy/reliability in the description of these specific states, the qualitative inference that they represent the location of an experimentally accessible state, is still reliable.

\section{Results and discussion}

\subsection{Bases vs analogues}

Calculations on each of the canonical bases (Table 1) show only a few states present below the $5 \mathrm{eV}$ threshold, with each of these states presenting a negligible TPA cross-section value. It is, therefore, relatively clear that application of TPA methodologies to the canonical bases directly is not an applicable strategy. However, the lack of interference from the canonical bases in regards to a competing TPA spectra can be considered an added benefit to the use of analogue probes within a larger DNA structure.

In contrast, a key feature of the analogues (Tables 2, 3, and S2) is the presence of accessible states at significantly lower energies compared to their canonical counterparts.

Amongst the purine analogues, a distinction can be made between the behaviour of the analogues that closely resemble the structures of the canonical purine bases (Table 3), and those such as $\mathbf{q A}$ (Table 2), which show a more significant structural deviation from the canonical base they emulate.

Analogues showing high structural similarity with their base counterpart (Table 3) show a similar, yet red-shifted, spread of accessible states when compared to adenine and guanine. While significantly more states are present below the $5 \mathrm{eV}$ threshold, very few of these states present a reasonable cross section when compared to both the canonical bases, and other analogues with the highest cross section being assigned to $\mathrm{S}_{7}$ of 6-MI. However, this state lies at $4.56 \mathrm{eV}(\approx 272 \mathrm{~nm})$, too high for reasonable use within a biological environment.

The spectra of those adenine analogues showing more significant structural deviations (Table 2) present a more complex range of states, despite being a relatively similar family of molecules. Of particular interest are $\mathbf{p A}$ and $\mathbf{q A n i -}$ tro, both of which exhibit an $S_{1}$ state with a high crosssectional values of 48.2 and $42.6 \mathrm{GM}$ at 2.90 and $1.96 \mathrm{eV}$, respectively, compared to an experimental value for $\mathbf{p A}$ of 6.6 GM; these $\pi-\pi^{*}$ states both show charge transfer character from the purine moiety to the portion of the analogue furthest from the hydrogen bonding centres, a character that is particularly pronounced in qAnitro; both analogues 
Table 1 QR-BLYP/cc-pVTZ state energies (eV [nm]) and two-photon cross sections (GM) of canonical bases and their Watson-Crick base paired dimers

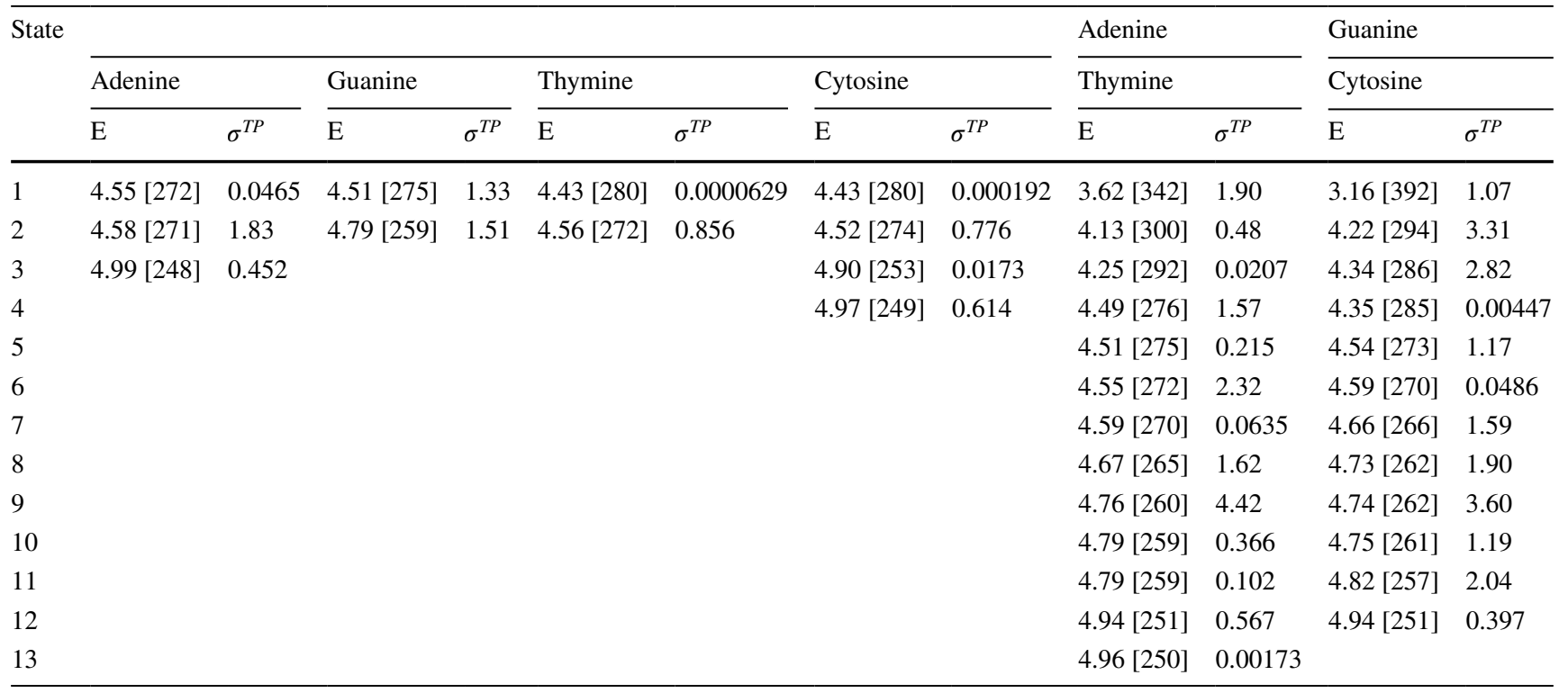

Table 2 QR-BLYP//cc-pVTZ state energies $(\mathrm{eV}[\mathrm{nm}])$ and two-photon cross sections (GM) of quadracyclic adenine $(\mathbf{q A})$ family of purine analogues

\begin{tabular}{|c|c|c|c|c|c|c|c|c|}
\hline \multirow{3}{*}{$\begin{array}{l}\text { State } \\
\text { Exp }\end{array}$} & \multicolumn{2}{|l|}{$\mathrm{qA}$} & \multicolumn{2}{|l|}{ qAN1 } & \multicolumn{2}{|l|}{ qAnitro } & \multicolumn{2}{|l|}{$\mathrm{pA}$} \\
\hline & $\mathrm{E}$ & $\sigma^{T P}$ & $\mathrm{E}$ & $\sigma^{T P}$ & $\mathrm{E}$ & $\sigma^{T P}$ & $\mathrm{E}$ & $\sigma^{T P}$ \\
\hline & & & & & & & 3.18 [390] & $5.3[38,68]$ \\
\hline 1 & $3.26[380]$ & 1.05 & 3.18 [390] & 6.59 & 1.96 [633] & 42.6 & 2.90 [428] & 48.2 \\
\hline 2 & 3.45 [359] & 13.2 & $3.32[373]$ & 11.8 & 3.04 [408] & 0.136 & 3.35 [370] & 17.6 \\
\hline 3 & 4.08 [304] & 4.44 & $4.07[305]$ & 2.72 & 3.08 [403] & 0.0715 & $3.46[358]$ & 2.05 \\
\hline 4 & 4.38 [283] & 3.32 & 4.17 [297] & 0.276 & 3.36 [369] & 3.64 & 3.90 [318] & 51.4 \\
\hline 5 & 4.47 [277] & 3.09 & $4.42[281]$ & 3.37 & 3.46 [358] & 28.3 & 3.96 [313] & 0.731 \\
\hline 6 & $4.51[275]$ & 25.4 & $4.46[278]$ & 32.8 & 3.59 [345] & 53.1 & 3.98 [312] & 0.455 \\
\hline 7 & 4.66 [266] & 0.283 & $4.52[274]$ & 0.0517 & $3.65[340]$ & 0.000589 & 4.17 [297] & 34.8 \\
\hline 8 & 4.78 [259] & 20.1 & $4.56[272]$ & 0.0316 & $3.82[325]$ & 0.268 & 4.33 [286] & 132 \\
\hline 9 & $4.87[255]$ & 4.67 & $4.77[260]$ & 19.3 & 4.22 [294] & 1440 & 4.39 [282] & 0.109 \\
\hline 10 & & & 4.77 [260] & 0.284 & 4.28 [290] & 1290 & $4.51[275]$ & 11.0 \\
\hline 11 & & & $4.85[256]$ & 7.080 & $4.30[288]$ & 0.107 & 4.59 [270] & 28.8 \\
\hline 12 & & & & & 4.34 [286] & 5.60 & $4.66[266]$ & 0.762 \\
\hline 13 & & & & & $4.52[274]$ & 14.2 & $4.67[265]$ & 34.4 \\
\hline 14 & & & & & 4.63 [268] & 340 & $4.73[262]$ & 0.0639 \\
\hline 15 & & & & & 4.68 [265] & 15.1 & $4.90[253]$ & 1.17 \\
\hline
\end{tabular}

also show additional states possessing high cross sections between 3.50-4.00 eV. It is also worth noting that qAnitro also presents an additional set of states with exceptionally high cross sections at $\approx 4.25 \mathrm{eV}$; these states are, however, significantly higher than would be ideal for use in a biochemical environment. In comparison, $\mathbf{q A}$ and $\mathbf{q A N 1}$ possess a more muted spectra with the lowest lying state for each analogue lying at $\approx 3.20 \mathrm{eV}$. This trend in cross-sectional values, coupled with analysis of the orbitals involved in high cross-section transitions (Fig. 4), suggests that creating an electronic alteration to the upper ring of the qA molecule to promote charge transfer character in the excited state can have a significant effect on the cross sections of accessible states.

Analogues for the pyrimidine bases (Fig. 2), involving significant structural variations when compared to their canonical base counterpart (Fig. 1), show the red-shifted spectra associated with all analogues, along with significantly increased cross-sectional values across the majority of the spectra (Table S2). However, due to the low density 
Table 3 QR-BLYP//cc-pVTZ state energies $(\mathrm{eV}[\mathrm{nm}])$ and two-photon cross sections (GM) of purine analogues

\begin{tabular}{|c|c|c|c|c|c|c|}
\hline \multirow[t]{2}{*}{ State } & \multicolumn{2}{|l|}{$2 \mathrm{AP}$} & \multicolumn{2}{|l|}{$6 \mathrm{MAP}$} & \multicolumn{2}{|l|}{ 6-MI } \\
\hline & $\mathrm{E}$ & $\sigma^{T P}$ & $\mathrm{E}$ & $\sigma^{T P}$ & $\mathrm{E}$ & $\sigma^{T P}$ \\
\hline Exp & 4.25 [292] & $0.2[30]$ & $3.76[330]$ & $3.4[66]$ & $3.31[375]$ & $2.5[65]$ \\
\hline 1 & $3.90[318]$ & 1.91 & $3.30[376]$ & 0.00375 & $3.58[346]$ & 0.0182 \\
\hline 2 & $4.01[309]$ & 0.0217 & $3.46[358]$ & 4.48 & $3.58[346]$ & 5.11 \\
\hline 3 & 4.83 [257] & 0.134 & $3.61[343]$ & 0.00279 & $4.00[310]$ & 0.00129 \\
\hline 4 & 4.98 [249] & 0.0415 & 4.01 [309] & 2.56 & 4.18 [297] & 0.00174 \\
\hline 5 & & & $4.33[286]$ & 0.00808 & 4.25 [292] & 4.51 \\
\hline 6 & & & $4.53[274]$ & 3.21 & $4.43[280]$ & 0.00712 \\
\hline 7 & & & $4.54[273]$ & 0.00198 & $4.56[272]$ & 12.0 \\
\hline 8 & & & $4.73[262]$ & 0.0138 & $4.76[260]$ & 0.0033 \\
\hline 9 & & & $4.96[250]$ & 0.00849 & $4.82[257]$ & 9.51 \\
\hline
\end{tabular}

of states found in these analogues, the majority of states showing cross sections of greater than $10 \mathrm{GM}$ lie at too high an energy to be ideal for the application of TPA methods to an in vivo environment. Exceptions to this can be seen in the 1,3-diaza-2-oxophenoxazine analogue $\left(\mathbf{t} \mathbf{C}^{O}\right)$ and its sulphonated equivalent, tC. Both of these compounds present $S_{2}$ and $S_{3}$ states that lie at relatively low energy, and possess high cross-section values; with the $S_{3}$ state of $\mathbf{t C}{ }^{O}$, at $3.91 \mathrm{eV}$, showing the largest cross section of $24.8 \mathrm{GM}$. In the case of both $\mathbf{t C}{ }^{O}$ and $\mathbf{t C}$, the $S_{3}$ state presents $\pi-\pi^{*}$ character resulting in charge transfer from the pyrimidine moiety into the extended structural manifold; in $\mathbf{t C}{ }^{O}$ the charge is dispersed across the upper rings of the modified structure; in comparison, charge is isolated more readily on the additional group VI heteroatom (sulphur) of $\mathbf{t C}$. In contrast, the $S_{2}$ state of tC ${ }^{O}$, at $3.79 \mathrm{eV}$ and $19.1 \mathrm{GM}$, shows $\pi-\pi^{*}$ in which charge is isolated to the pyrimidine moiety.

The values presented for these analogues in an isolated state highlight the significant potential for applicability in TPA-based spectroscopic analysis, particularly pertaining to identification of transport and localisation pathways within a cell. However, little can be inferred from these data as to the robustness of the spectra of each analogue to electronic interference, commonly brought about through interactions with surrounding bases.

\subsection{Effects of $\mathrm{H}$-bonding within Watson-Crick base pairs}

The formation of Watson-Crick base pairs between the canonical bases (Fig. 1) produces a TPA spectra which can be primarily described as an overlap of the monomeric spectra. The most notable change in the dimers (Table 1), when compared to the isolated bases, is a significant reduction in the $S_{1}$ energies. However, no significant change is observed in the cross-section values for the states considered.
Given the relatively weak TPA spectra of the canonical bases (Table 1) when compared to their analogues (Tables 2, 3, and S2), combined with the nature of the intramolecular hydrogen-bond network, dimers formed between a canonical base and an analogue of its corresponding Watson-Crick pair can be described as falling into one of three categories. These categories, described by the character of TPA-accessible $\pi-\pi^{*}$ states are: (i) excitations to states with high TPA cross sections are isolated solely to the analogue structure with little or no charge crossing the hydrogen-bond network; (ii) excitations show movement of charge across the hydrogen-bond network, whether from base to analogue or vice versa; (iii) formation of the dimeric structure results in the activation of the canonical base such that excitations to some states present minimal electronic character on the analogue.

\subsubsection{Base pairs with adenine}

Dimer formation between adenine and ${ }^{d i o x} \mathbf{T}(\mathbf{A - d i o x} \mathbf{T})$ results in the transitions isolated to the analogue and equating to the monomeric high cross-section states (Table 4) undergoing a red shift of $\approx 0.2 \mathrm{eV}$ (Table S2); additionally, three new high cross-section states are introduced. Of particular interest, however, is $S_{13}$, the lowest lying high cross-section state of the dimer and presenting $\pi-\pi^{*}$ character solely isolated on the adenine residue; this relatively low lying photoactivation of the canonical base, observed in a number of dimeric structures, presents an intriguing avenue of investigation in the development of targetted photodynamic methodologies.

In comparison, A-6AzaO and A-6AzaS show relatively unaltered spectra in terms of the spread of high crosssection states though with a notable reduction of the crosssection values (Table $\mathrm{S} 2$ ). 
Table 4 QR-BLYP//cc-pVTZ state energies (eV [nm]) and two-photon cross sections (GM) of pyrimidine analogues

\begin{tabular}{|c|c|c|c|c|c|c|c|c|c|c|c|c|}
\hline \multirow[t]{2}{*}{ State } & \multicolumn{2}{|l|}{${ }^{d i o x} \mathrm{~T}$} & \multicolumn{2}{|l|}{$6 \mathrm{AzaO}$} & \multicolumn{2}{|l|}{ 6AzaS } & \multicolumn{2}{|l|}{${ }^{D M A} C$} & \multicolumn{2}{|l|}{$\mathrm{tC}^{O}$} & \multicolumn{2}{|l|}{$\mathrm{tC}$} \\
\hline & $\mathrm{E}$ & $\sigma^{T P}$ & $\mathrm{E}$ & $\sigma^{T P}$ & $\mathrm{E}$ & $\sigma^{T P}$ & $\mathrm{E}$ & $\sigma^{T P}$ & $\mathrm{E}$ & $\sigma^{T P}$ & $\mathrm{E}$ & $\sigma^{T P}$ \\
\hline Exp & & & & & & & & & & & $3.10[400]$ & $1.5[30]$ \\
\hline 1 & 3.55 [349] & 2.25 & $3.49[355]$ & 7.42 & $3.58[346]$ & 4.73 & $2.74[452]$ & 1.77 & 3.16 [392] & 5.05 & 3.08 [402] & 4.95 \\
\hline 2 & 4.22 [294] & 0.00314 & 4.17 [297] & 0.00184 & $4.05[306]$ & 0.211 & $3.87[320]$ & 0.113 & 3.79 [327] & 19.1 & 3.66 [339] & 2.60 \\
\hline 3 & 4.30 [288] & 6.26 & 4.36 [284] & 1.53 & 4.22 [294] & 9.27 & 4.09 [303] & 30.7 & $3.91[317]$ & 24.8 & 3.72 [333] & 18.1 \\
\hline 4 & $4.70[264]$ & 30.9 & $4.79[258]$ & 68.5 & 4.26 [291] & 14.1 & $4.23[293]$ & 3.32 & 4.18 [297] & 0.00147 & $3.96[313]$ & 5.71 \\
\hline 5 & $4.88[254]$ & 0.0105 & $4.85[256]$ & 0.00205 & $4.77[260]$ & 117 & 4.33 [286] & 2.48 & 4.18 [297] & 9.98 & 4.15 [299] & 2.81 \\
\hline 6 & 4.99 [248] & 20.1 & 4.98 [249] & 73.5 & 4.82 [257] & 0.459 & 4.47 [277] & 8.71 & $4.49[276]$ & 5.12 & 4.33 [286] & 0.87 \\
\hline 7 & & & & & $4.93[251]$ & 0.16 & 4.48 [277] & 19.0 & $4.70[264]$ & 0.323 & $4.46[278]$ & 2.75 \\
\hline 8 & & & & & & & $4.74[262]$ & 3.95 & $4.81[258]$ & 0.0346 & 4.61 [269] & 1.41 \\
\hline 9 & & & & & & & & & $4.88[254]$ & 4.90 & 4.67 [265] & 0.144 \\
\hline 10 & & & & & & & & & & & $4.70[264]$ & 0.567 \\
\hline
\end{tabular}

\subsubsection{Base pairs with guanine}

Analogues for the cytosine base, when dimerised with guanine, present a blue-shifted spectra when compared to the adenine dimers formed with thymine analogues; this blue-shifted spectra were also observed in the monomeric structures.

While $S_{14}$ of the $\mathbf{G}-{ }^{D M A} \mathbf{C}$ dimer shows a slight increase in cross-section value compared to the monomer (Table 4), the most striking feature of the G-B dimers is the near complete reduction of activity in the sub-5 eV region of the G-tC dimer. This reduction can be primarily attributed to the hydrogen bonds formed with the guanine base causing a significant blue-shift in the spectra of the tC analogue while the spectra of the guanine itself is relatively unaffected.

\subsubsection{Base pairs with thymine}

In a similar manner to the spectra of the Watson-Crick hydrogen bonded pair, the spectra involving analogues to the adenine base, when hydrogen bonded to the thymine base (Table S2), can be considered as a simple overlap of the monomeric spectra with minimal effects of hydrogen bond formation on either structure. While negligible shift is observed in the dimeric spectra, some notable reduction is observed. This reduction can be seen in states $S_{12}$ and $S_{14}$ of $\mathbf{q A}$, though the cross section of $S_{3}$ remains relatively unchanged; and states $S_{14}$ and $S_{25}$ of qAN1. However, notably, the cross-section values of T-qAnitro and $\mathbf{T}-\mathbf{p A}$ remain relatively unchanged when compared to their monomeric spectra (Table 2).

\subsubsection{Base pairs with cytosine}

The C-6-MI (Table 2) dimer also presents a spectra described predominantly as an overlap of the cytosine and 6-MI spectra (Tables 1 and 3, respectively). However, a new low-energy, high cross-section state is observed in the $S_{2}$ position $(3.46 \mathrm{eV})$ which presents a reasonable cross-section $(15.8 \mathrm{GM})$ when compared to the more prominent analogues (e.g. qAnitro and $\mathbf{p A}$ ).

\subsection{Effects of nucleobase $\pi$-stacking}

Compared to the changes in the spectra of each analogue upon the formation of a hydrogen bonded dimers (Tables $\mathrm{S} 2$ and S3), the effects of $\pi$-stacking (Tables S6-S13) are much more pronounced. In a manner similar to that of the hydrogen-bonded dimers, interactions between the $\pi$-stacked monomers do open a number of charge transfer states not present in either monomer; however, the most notable, and key, observation is that $\pi$-stacking interactions appear to result in a severe reduction in cross-section value in a large number of the high cross-section states discussed so far. It is worth note that, while the reduction in cross section does bring the QR-DFT values more in line with those observed experimentally even the largest reductions, observed when $\pi$-stacking with the thymine base (Table S12), do not on their own provide an explanation for the discrepancy noted between the experimental and theoretical results.

While this observation is not necessarily the most surprising due to the predominantly $\pi-\pi^{*}$ nature of the excited states of the analogues, these data act to strongly reaffirm that effects of $\pi$-stacking on new analogue candidates can, and should, act as a major design consideration when 
quantifying their feasibility, even before the candidates are tested in a more harsh, in vivo environment.

These trends, consisting primarily of reduction of lower lying states with a rare observation of new high cross-section states is reliably observed when considering the analogues as they $\pi$-stack with each canonical base.

\subsubsection{Purine analogue $\pi$-stacking}

In a similar manner to the formation of hydrogen-bonded dimers (Tables S2 and S3), a distinction can be readily drawn between those purine analogues possessing an extended structure (qA, qAN1, qAnitro, and $\mathbf{p A}$ ), and those more closely resembling their canonical counterparts (2AP, 6MAP, and 6-MI). Of the more structurally similar analogues, 2AP is rendered relatively inaccessible in the sub-5 $e V$ region and 6MAP presents only a pair of high-energy accessible states at $S_{24}$ and $S_{25}$, each lying just under $5 \mathrm{eV}$. The B- $\pi-6$ MI dimers are also observed to undergo significant reduction of their cross-section values up exposure to a $\pi$-stacking environment (Table 3 ).

As with both the isolated monomers (Table 2) and the hydrogen-bonded dimers (Table S3), the spectra of the $\pi$ -stacked dimers of the $\mathbf{q A}$ family of analogues appear to be significantly more accessible than the smaller purine analogues, with particularly promising high cross-section states at the lower-energy regions of each spectra. The starting moiety for this family, $\mathbf{q A}$, shows a notable degree of variation in the spectra depending on the base with which it is interacting; $\pi$-stacking with a purine base results in the relative reduction of the low energy states $(\approx 3.4 \mathrm{eV})$ as well as the higher energy states $(\approx 4.7 \mathrm{eV})$, while only a small reduction in cross-section value is observed when stacked with a pyrimidine base.

The alteration of the outer phenyl moiety of qA to the pyridyl moiety found in qAN1 does not appear to alter the trend observed $\pi$-stacking. However, a notable observation in the $\mathbf{B}-\pi$-qAN1 spectra is the significant reduction of the monomeric $S_{6}$ state (Table 2) upon formation of a $\pi$-stacking interaction, regardless of the base.

Despite the reduction effects of the $\pi$-stacking interactions, qAnitro remains most accessible of the analogues studied here. Of particular interest is the monomeric $S_{1}$ state (Fig. 4) which, as well as occurring at a low energy $(\approx 1.95$ $e V$ ), maintains a high cross-section value in each of the $\mathbf{B}-\pi$ -qAnitro dimers, with only the $\mathbf{G}-\boldsymbol{\pi}-\mathbf{q A A n i t r o}$ dimer showing any significant reduction in cross-section value. A notable characteristic of these transitions is that, even in the presence of the $\pi$-stacked environment, there is minimal change to the overall excited state character (Fig. 5). In comparison, the $S_{4}$ state of the qAnitro monomer $(4.58 \mathrm{eV} ; 14.4 \mathrm{GM})$ is quenched in each of the $\mathbf{B}-\pi$-qAnitro dimer, with the exception of T- $\pi-\mathbf{q}$ Anitro where it is slightly destabilised $(\Delta E=$
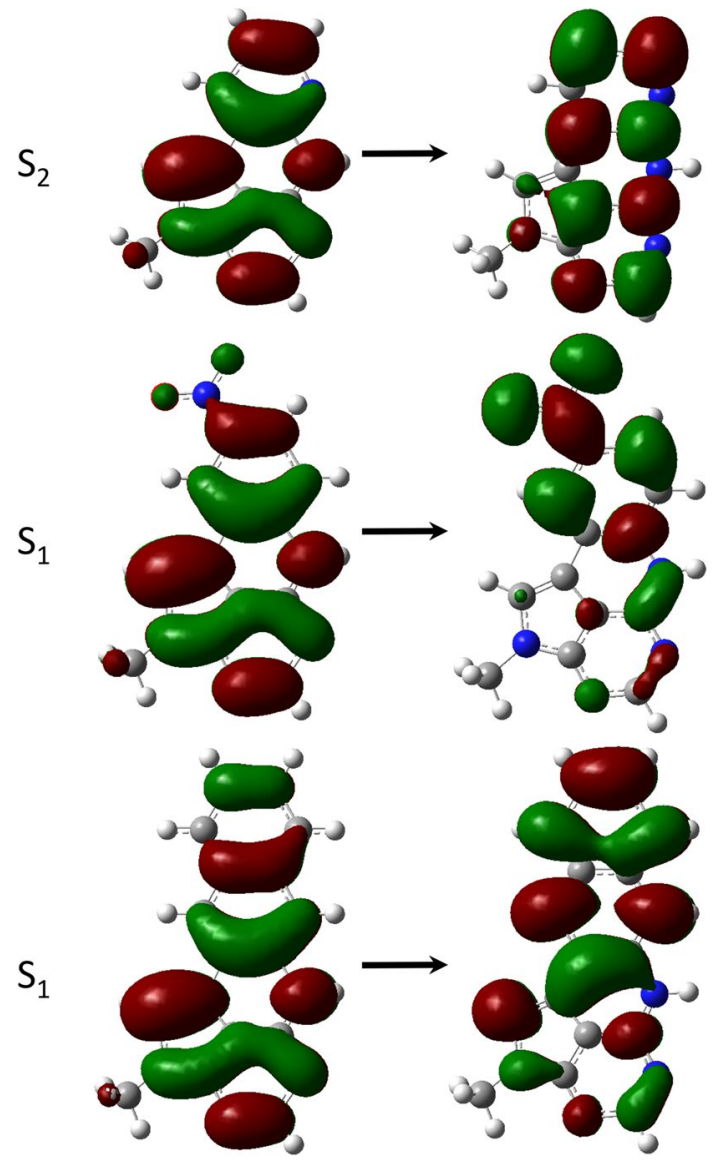

Fig. 4 Lowest lying states presenting high cross sections, as determined by QR-BLYP//cc-pVTZ, within the TPA manifold, of each modified member of the quadracyclic adenine $(\mathbf{q A})$ family of analogues. qAN1, top; qAnitro, middle; pA, bottom

$0.04 \mathrm{eV})$ and the cross section (15.5 GM) remains in the same range as that of the monomer (Table 2). Additionally, a number of dimer specific high cross-section states are observed in the 3.9-4.6 A region (Tables S6-S9), determined by base specific shifting of the monomeric $S_{9}, S_{10}$, and $S_{14}$ states (Table 2).

Regarding the overall chemistry of the qAnitro analogue: while the excited-state chemistry in the hydrogen bonded dimers appears to be dominated by the drawing of charge towards the $\mathrm{NO}_{2}$ group of qAnitro, upon $\pi$-stacking, that chemistry would appear to be inverted, with the majority of high cross-section states implying the movement of charge away from the $\mathrm{NO}_{2}$ moiety either onto the interacting base, or throughout the dimeric structure.

Contrary to most of the other purine analogues, B- $\pi$ -pA dimers (Tables S6-S9) show minimal change to their spectra when compared to that of the $\mathbf{p A}$ monomer (Table 2) with the most notable effect of $\pi$-stacking being mild reduction observed across each $\mathbf{B}-\boldsymbol{\pi}-\mathbf{p} \mathbf{A}$ spectra. However, due to the large cross sections observed in 

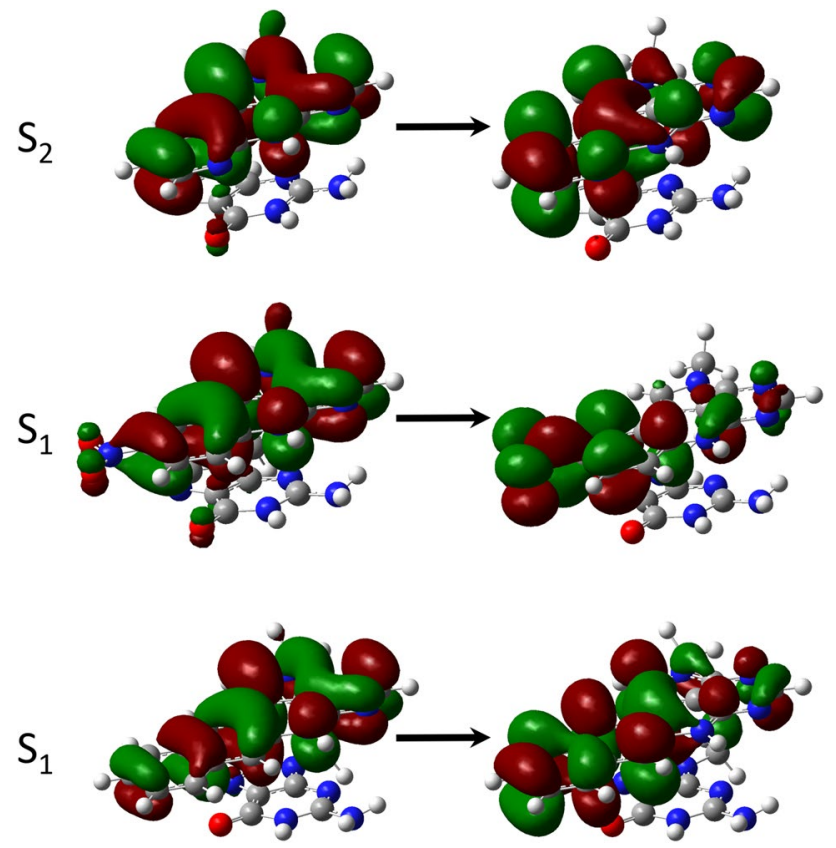

Fig. 5 Lowest lying states presenting high cross sections, as determined by QR-BLYP//cc-pVTZ, within the TPA manifold, of each modified member of the quadracyclic adenine $(\mathbf{q A})$ family of analogues upon $\pi$-stacking with the guanine base. qAN1, top; qAnitro, middle; pA, bottom

the pA spectrum, even when quenched by the $\pi$-stacking interactions, most high cross-section states still remain viable targets. The $\pi$-stacking interactions formed with the pyrimidine bases (Tables S8 \& S9) appear to have more of an effect than their purine counterparts with the $\mathbf{T}-\pi$-pA dimer presenting the largest reduction in the cross-section value of the high-interest $S_{1}$ state.

\subsubsection{Pyrimidine analogues $\pi$-stacking}

In comparison to the purine analogues, $\pi$-stacked spectra of pyrimidine analogues (Tables S10-S13) show significantly less variation when compared to their monomeric counterparts (Table S2) with regards to the energetic shifting of states in addition to the introduction of additional states under the $5 \mathrm{eV}$ threshold. This reduced variation is observed across the studied analogues in spite of the high degree of structural variation involved in the analogue structures (Fig. 2).

Across each of the spectra studied through this work, only the high energy states of the $\mathbf{B}-\pi-6 \mathbf{A z a O}$ and $\mathbf{B}-\pi$ -6AzaS structures $(\approx 4.8 \mathrm{eV})$, as well as the lower energy states of the $\mathbf{B}-\pi$ - $\mathrm{tC}^{O}$ and $\mathbf{B}-\pi$-tC dimers $(\approx 3.8 \mathrm{eV})$ remain relatively accessible.

\section{Conclusion and outlook}

The applicability of expanding the use of modern nucleotide base analogues to include two-photon spectroscopic methodologies is evident from the data presented throughout this work; however, these data also highlight that, while a number of analogues assessed would warrant use in an in vitro or ex vivo setting, the vast majority of the states possessing a sufficiently large cross-section value are at a wavelength too high to allow for the tissue penetration desirable in an in vitro or in cellulo setting. Of the analogues studied here, only qAnitro and $\mathbf{p A}$, with an $S_{1}$ state significantly under the $3 \mathrm{eV}$ mark and cross-section values consistently over 20.0 GM across both hydrogen bonded and $\pi$-stacked dimeric structures (Tables S3, S6-S9) stand out as potential as candidate for use with TPA methodologies. However, given that qAnitro is not reported to fluoresce, it cannot be recommended for use as this property is independent of the OPA or TPA methods used. Instead, we can look to the structure of qAnitro, coupled with the newly presented ABN analogue [67], for insight into the design of analogues with high cross sections. As can be seen in the orbital transitions of qAnitro (figures $4 \& 5$ ), and the word done by Samaan et. al. [67], there is significant merit in pursuing the construction of a push-pull motifs, commonly considered a hallmark of optically bright organic fluorophores, as a mechanism for enhancing the TPA cross section of future FBAs.

In comparison, the next best candidates ( $\mathbf{t} \mathbf{C}$ and $\mathbf{t C}$ $o$ ), while presenting high cross-section $\pi-\pi^{*}$ states in the sub- $4 \mathrm{eV}$ region, these are quenched upon $\pi$-stacking with any base (Tables S10 - S13), resulting in the lowest lying high cross-section state across all environments being calculated in the 4-5 eV range; however, the environmental dependence of the low-lying state of $\mathbf{t C}$ may find use in niche situations in following the incorporation pathways of nucleotide bases throughout the cell.

Throughout this study, a number of design and testing principals have begun to emerge as worth addressing in regards to the development of new two-photon-based analogues for the canonical bases. Primary amongst these is the need for the promotion of lower-lying high cross-section states to enhance applicability in an in vivo environment; particularly given the observation that only qAnitro and $\mathbf{p A}$ present high cross-section states in the sub- $3 \mathrm{eV}$ region both of which lie just within the ideal range for tissue penetration [120-122]. The second, stand-out, design consideration is that the $\pi$-stacking environment represents a substantial factor in the accessibility of low-lying states. The data presented here would also suggest that the presence of an extended, conjugated, polycyclic framework within the analogue structure has a significant effect of 
the two-photon cross sections of an analogue. In addition, the effects of changing from the phenyl moiety of $\mathbf{q A}$ to a more electron withdrawing pyridyl moiety as seen in qAN1, or the inclusion of a strong electron withdrawing group, such as $\mathrm{NO}_{2}$ present on qAnitro, shows that it is possible to promote the preservation of the monomeric spectra in a dimeric environment by preventing the distribution of charge through the incorporation of small electronic substituents, presenting a promising design feature for the development of novel analogues with a higher fluorescent capacity.

One of the primary effects of including these modifications is to move charge away from both the hydrogen-bonding and $\pi$-stacking environments (Fig. 4), acting to protect the excited state character from the changing chemical environment (Fig. 5), preserving the high cross-section values that define the modified members of the $\mathbf{q A}$ family of analogues. In light of this, the investigation of the effects of dedicated electron donating and withdrawing groups would be warranted to assess the potential of local base activation with the aim of moving from biochemical probes to the potential for gene targetted photosensitising compounds.

Given the design principles discussed here, it would follow that the development of two-photon analogues relating to $\mathbf{A}$ and $\mathbf{C}$ would offer significantly more design flexibility than those relating to the structures of $\mathbf{G}$ or $\mathbf{T}$; this is primarily due to the idea that any addition to the structure is more limited when there is a need to preserve the carbonyl group involved in the hydrogen-bonding of $\mathbf{G}$ or $\mathbf{T}$. This, in comparison to the amino group found on $\mathbf{A}$ and $\mathbf{C}$, can still effectively take part in the hydrogen-bonding network whether as a primary amine $\left({ }^{D M A} \mathbf{C}, 2 \mathrm{AP} \& \mathbf{6 M A P}\right)$ or as a secondary amine $\left(\mathbf{t} \mathbf{C}^{O}, \mathbf{t C}\right.$, and the $\mathbf{q A}$ family of analogues). There is potential for investigation into the effects of substitution of the hydrogen-bonding carbonyl group of $\mathbf{G}$ and $\mathbf{T}$ for an imine group $(-\mathrm{N}=)$ to preserve an accessible lone pair while allowing for extension of the polycyclic framework, but it is uncertain how this would effect the hydrogen-bond framework of these compounds.

In the design of future analogue, it is worth noting that a common property in the majority of the analogues studied is the presence of a minimal to negligible permanent dipole moment in comparison to highly TPA active organic photophores. This results in a reliance solely on effects of the transition dipole between the ground and excited state, a single factor in the determination, and scaling, of the TPA viability of a molecule [123-125]. The investigation of novel analogues specifically designed to incorporate a permanent dipole may open up new avenue in the development of promising TPA candidates; this avenue, however, will come with challenges presented in maintaining the permanent dipole throughout the differing hydrogen-bonding and $\pi$-stacking environments experienced by the analogues.
This investigation also highlighted that, while providing valuable insight into the photochemistry of these compounds, the inclusion of either hydrogen-bonding or $\pi$-stacking effects with a single nucleobase was insufficient to explain the discrepancy observed between the theoretical and experimental results. Further investigation is warranted to determine appropriate quantitative improvements to the model system utilised for similar and future studies. These improvements may involve the inclusion of: i) more than one $\pi$-stacking base to sandwich the analogue; ii) the ribose sugar, which may have an effect on both the geometry adopted and the excited state character; iii) explicit solvent molecules and key coordination sites; and iv) the combination of both $\pi$-stacking and hydrogen-bonding effects within the same calculations. Due to the, potentially drastic, increase size of models accounting for these additions the use of alternative methodologies, better equipped to deal with larger structures, should also be probed, including the use of: the Cholesky decomposition; resolution of identity; or entangled TPA methodologies.

In conclusion, while the majority of current nucleotide base analogues do not lend themselves to uses with two-photon methodologies, there are a number of promising candidates as well as significant design potential for the targetted development not only of novel, two-photon dedicated analogues, but also in the development of analogues specifically designed to take advantage of both the increased resolution and tissue penetration of two-photon methodologies in the design of photosensitising compounds that can be embedded in to a given DNA primer to enable photoinduced, gene sequence targetted, DNA damage whether in pathogens, or in cancer cells.

Supplementary Information The online version contains supplementary material available at https://doi.org/10.1007/s43630-022-00182-7.

Acknowledgements T.M. thanks the The High End Computing facility at Lancaster University.

Author Contributions Not Applicable.

\section{Declarations}

Conflict of interest The author declare that they have no conflict of interest.

Availability of data and materials Not Applicable.

Code Availability Not Applicable.

Funding Not Applicable.

Open Access This article is licensed under a Creative Commons Attribution 4.0 International License, which permits use, sharing, adaptation, distribution and reproduction in any medium or format, as long as you give appropriate credit to the original author(s) and the source, provide a link to the Creative Commons licence, and indicate if changes were made. The images or other third party material in this article are 
included in the article's Creative Commons licence, unless indicated otherwise in a credit line to the material. If material is not included in the article's Creative Commons licence and your intended use is not permitted by statutory regulation or exceeds the permitted use, you will need to obtain permission directly from the copyright holder. To view a copy of this licence, visit http://creativecommons.org/licenses/by/4.0/.

\section{References}

1. Hong, S., \& Cheng, X. (2016). DNA base flipping: A general mechanism for writing, reading, and erasing DNA modifications. Advances in Experimental Medicine and Biology, 945, 321.

2. Ratel, D., Ravanat, J. L., Berger, F., \& Wion, D. (2006). N6-methyladenine: The other methylated base of DNA. BioEssays, 28, 309.

3. Wu, T. P., Wang, T., Seeting, M. G., Lai, Y., Zhu, S., Lin, K., Liu, Y., Byrum, S.D., Mackintosh, S.G., Zhong, M., Tackett, A., Wang, G., Fang, L.S.H. adn G., Swenberg, J.A., \& Xiao, A.Z. (2016). DNA methylation on N(6)-adenine in mammalian embryonic stem cells. Nature, 532, 329.

4. Ceder, H., \& Bergman, Y. (2012). DNA methylation on N(6)adenine in mammalian embryonic stem cell. Programming of DNA methylation patterns, 81, 97.

5. Beard, C., Li, E., \& Jaenisch, R. (1995). Loss of methylation activates Xist in somatic but not in embryonic cells. Genes \& Development, 9, 2325.

6. Borgel, J., Guibert, S., Li, Y., Chiba, H., Schübeler, D., Sasaki, H., Forné, T., \& Weber, M. (2010). Targets and dynamics of promoter DNA methylation during early mouse development. Nature Genetics, 42, 1093.

7. Lindahl, T. (1993). Instability and decay of the primary structure of DNA. Nature, 362, 709.

8. Cavalieri, E., Saeed, M., Zahid, M., Cassada, D., Snow, D., Miljkovic, M., \& Rogan, E. (2012). Mechanism of DNA depurination by carcinogens in relation to cancer initiation. IUBMB Life, 64, 169.

9. Han, M. J., Cho, T. J., Kim, K. H., Yoo, K. S., Park, Y. D., \& Chang, J. Y. (2000). Depyrimidination of synthetic poly(uridylic acid) analogue. Journal of Polymer Science Polymer Chemistry, $38,423$.

10. Sischka, A., Toensing, K., Eckel, R., Wilking, S. D., Sewald, N., Ros, R., \& Anselmetti, D. (2005). Molecular mechanisms and kinetics between DNA and DNA binding ligands. Biophysical Journal, 88, 404.

11. Cerny, J., Kabelac, M., \& Hobza, P. (2008). Double-helical $\rightarrow$ ladder structural transition in the B-DNA is induced by a loss of dispersion energy. Journal of the American Chemical Society, $130,16055$.

12. Churchill, C. D. M., Navarro-Whyte, L., Rutledge, L. R., \& Wetmore, S. D. (2009). Effects of the biological backbone on DNA-protein stacking interactions. Physical Chemistry Chemical Physics, 11, 10657.

13. Sherrill, C. D. (2013). Energy component analysis of interactions. Accounts of Chemical Research, 46, 1020.

14. Riley, K. E., \& Hobza, P. (2013). On the importance and origin of aromatic interactions in chemistry and biodisciplines. Accounts of Chemical Research, 46, 927.

15. Swart, M., van der Wijst, T., Fonseca Guerra, C., \& Bickelhaupt, F. M. (2007). $\pi$ - $\pi$ stacking tackled with density functional theory. Journal of Molecular Modeling, 13, 1245.

16. Porter, J., Swart, M., Fonseca Guerra, C., \& Bickelhaupt, F. M. (2011). Selectivity in DNA replication. Interplay of steric shape, hydrogen bonds-stacking and solvent effects. Chemical Cоттиnications, 47, 7326.
17. Hesselmann, A., Jansen, G., \& Schutz, M. (2006). Interaction energy contributions of $\mathrm{H}$-bonded and stacked structures of the AT and GC DNA base pairs from the combined density functional theory and intermolecular perturbation theory approach. Journal of the American Chemical Society, 128, 11730.

18. Šponer, J., Leszczynski, J., \& Hobza, P. (2001). Electronic properties, hydrogen bonding, stacking, and cation binding of DNA and RNA bases. Biopolymers, 61, 3 .

19. Guerra, C. F., Adn, F. M. B., Snijders, J. G., \& Baerends, E. J. (1999). The nature of the hydrogen bond in DNA base pairs: The role of charge transfer and resonance assistance. Chemistry-A European Journal, 5, 3581.

20. Guerra, C. F., Adn, F. M. B., Snijders, J. G., \& Baerends, E. J. (2000). Hydrogen bonding in DNA base Pairs: Reconciliation of theory and experiment. Journal of the American Chemical Society, 122, 4117.

21. Bose, A., Thomas, I., Kavitha, G., \& Abraham, E. (2018). Fluorescence spectroscopy and its applications: A review. IJAPA, 8, 1.

22. Shahzad, A., Edetsberger, M., \& Koehler, G. (2010). Fluorescence spectroscopy: An emerging excellent diagnostic tool in medical sciences. Applied Spectroscopy Reviews, 45, 1.

23. Bachmann, L., Zezell, D. M., Ribeiro, A., D. C., Gomes, L., $\&$ Ito, A.S. (2006). Fluorescence spectroscopy of biological tissues - a review. Applied Spectroscopy Reviews, 41, 575.

24. Karoui, R., \& Blecker, C. (2011). Fluorescence spectroscopy measurement for quality assessment of food systems-a review. Food and Bioprocess Technology, 4, 364.

25. Karoui, R., \& Blecker, C. (2017). Single-molecule fluorescence spectroscopy of photosynthetic systems. Chemical Reviews, 117, 860.

26. Orden, A. V., \& Jung, J. (2008). Review fluorescence correlation spectroscopy for probing the kinetics and mechanisms of DNA hairpin formation. Biopolymers, 89, 1.

27. Hess, S. T., Huang, S., Heikal, A. A., \& Webb, W. W. (2002). Biological and chemical applications of fluorescence correlation spectroscopy: A review. Biochemistry, 41, 697.

28. Shahzad, A., Köhler, G., Knapp, M., Gaubitzer, E., Puchinger, M., \& Edetsberger, M. (2009). Emerging applications of fluorescence spectroscopy in medical microbiology field. Journal of Translational Medicine, 7, 99.

29. Dramićanin, T., \& Dramićanin, M. (2015). Using Fluorescence Spectroscopy to Diagnose Breast Cancer, Applications of Molecular Spectroscopy to Current Research in the Chemical and Biological Sciences (IntechOpen)

30. Lane, R. S. K., \& Magennis, S. W. (2012). Two-photon excitation of the fluorescent nucleobase analogues 2-AP and tC. RSC Advances, 2, 11397.

31. Hawkins, M. E. (2001). Fluorescent pteridine nucleoside analogs: A window on DNA interactions. Cell Biochemistry and Biophysics, 34, 257.

32. Rist, M. J., \& Marino, J. P. (2002). fluorescent nucleotide base analogs as probes of nucleic acid structure. Dynamics and interactions. Current Organic Chemistry, 6, 775.

33. Greco, N. J., \& Tor, Y. (2005). Simple fluorescent pyrimidine analogues detect the presence of DNA abasic sites. Journal of the American Chemical Society, 127, 10784.

34. Reha-Krantz, L. J., Hariharan, C., Subuddi, U., Xia, S., Zhao, C., Beckman, J., Christian, T., \& Konigsberg, W. (2011). Structure of the 2-aminopurine-cytosine base pair formed in the polymerase active site of the RB69 Y567A-DNA polymerase. Biochemistry, 50, 10136.

35. Malcomson, T., \& Paterson, M. J. (2020). Theoretical determination of two-photon absorption in biologically relevant pterin derivatives. Photochemical and Photobiological Sciences, 19, 1538. 
36. Widom, J. R., Rappoport, D., Perdomo-Ortiz, A., Thomsen, H., Johnson, N. P., von Hippel, P. H., Aspuru-Guzik, A., \& Marcus, A. H. (2013). Electronic transition moments of 6-methyl isoxanthopterin-a fluorescent analogue of the nucleic acid base guanine. Nucleic Acids Research, 41, 995.

37. Yang, K., Matsika, S., \& Stanley, R. J. (2007). 6MAP, a fluorescent adenine analogue, is a probe of base flipping by DNA photolyase. The Journal of Physical Chemistry B, 111, 10615.

38. Bood, M., Füchtbauer, A. F., Wranne, M. S., Ro, J. J., Sarangamath, S., El-Sagheer, A. H., Rupert, D. L. M., Fisher, R. S., Magennis, S. W., Jones, A. C., Höök, F., Brown, T., Kim, B. H., Dahlén, A., Wilhelmsson, L. M., \& Grøtli, M. (2018). Pentacyclic adenine: A versatile and exceptionally bright fluorescent DNA base analogue. Chemical Science, 9, 3494.

39. Wranne, M. S., Füchtbauer, A. F., Dumat, B., Bood, M., ElSagheer, A. H., Brown, T., Gradén, H., Grøtli, M., \& Wilhelmsson, L. M. (2017). Toward complete sequence flexibility of nucleic acid base analogue FRET. Journal of the American Chemical Society, 139, 9271.

40. Dierckx, A., Miannay, F., Gaied, N. B., Preus, S., Björck, M., Brown, T., \& Wilhelmsson, L. M. (2012). Quadracyclic adenine: A non-perturbing fluorescent adenine analogue. Chemistry-A European Journal, 18, 5987.

41. Dumat, B., Bood, M., Wranne, M. S., Lawson, C. P., Larsen, A. F., Preus, S., Streling, J., Gradeén, H., Wellner, E., Grøtli, M., \& Wilhelmsson, L. M. (2012). Quadracyclic adenine: A non-perturbing fluorescent adenine analogue. Chemistry-A European Journal, 18, 5987.

42. Sandin, P., Börjesson, K., Li, H., Mårtensson, J., Brown, T., Wilhelmsson, L. M., \& Albinsson, B. (2008). Characterization and use of an unprecedentedly bright and structurally non-perturbing fluorescent DNA base analogue. Nucleic Acids Research, 36, 157.

43. Sandin, P., Wilhelmsson, L. M., Lincoln, P., Powers, V. E. C., Brown, T., \& Albinsson, B. (2005). Fluorescent properties of DNA base analogue tC upon incorporation into DNA-negligible influence of neighbouring bases on fluorescence quantum yield. Nucleic Acids Research, 33, 5019.

44. Mata, G., \& Luedtke, N. W. (2015). Fluorescent probe for protoncoupled DNA folding revealing slow exchange of i-motif and duplex structures. Journal of the American Chemical Society, 137, 699.

45. Hirashima, S., Han, J. H., Tsuno, H., Tanigaki, Y., Park, S., \& Sugiyama, H. (2019). New size-expanded fluorescent thymine analogue: Synthesis, characterization, and application. Chemistry-A European Journal, 25, 9913.

46. Ward, D. C., Reich, E., \& Stryet, L. (1969). Fluorescence studies of nucleotides and polynucleotides. I. Formycin, 2-aminopurine riboside, 2,6-diaminopurine riboside, and their derivatives. Journal of Biological Chemistry 244, 1228.

47. Guest, C. R., Hochstrasser, R. A., Sower, L. C., \& Millar, D. P. (1991). Dynamics of mismatched base pairs in DNA. Biochemistry, 30, 3271.

48. Kelley, S. O., \& Barton, J. K. (1999). Electron transfer between bases in double helical DNA. Science, 283, 375.

49. Rachofsky, E. L., Osman, R., \& Ross, J. B. A. (2001). Probing structure and dynamics of DNA with 2-aminopurine: Effects of local environment on fluorescence. Biochemistry, 40, 946.

50. Neely, R. K., Daujotyte, D., Grazulis, S., Magennis, S. W., Dryden, D. T. F., Klimašauskas, S., \& Jones, A. C. (2005). Twophoton absorption spectra of fluorescent isomorphic DNA base analogs. Nucleic Acids Research, 33, 6963.

51. Jones, A., \& Neely, R. (2015). 2-Aminopurine as a fluorescent probe of DNA conformation and the DNA-enzyme interface. Quarterly Reviews of Biophysics, 48, 244.
52. Wilhelmsson, L. M., \& Rev, Q. (2010). Fluorescent nucleic acid base analogues. Biophysics, 43, 159.

53. Wilhelmsson, L. M., Sandin, P., Halmen, A., Albinsson, B., Lincoln, P., \& Norden, B. (2003). Photophysical Characterization of Fluorescent DNA Base Analogue, tC. The Journal of Physical Chemistry B, 107, 9094.

54. Sandin, P., Wilhelmsson, L. M., Lincoln, P., Powers, V. E. C., Brown, T., \& Albinsson, B. (2005). Fluorescent properties of DNA base analogue tC upon incorporation into DNA - negligible influence of neighbouring bases on fluorescence quantum yield. Nucleic Acids Research, 33, 5019.

55. Eggeling, C., Widengren, J., Rigler, R., \& Seidel, C. A. M. (1998). Photobleaching of fluorescent dyes under conditions used for single-molecule detection?. Evidence of two-step photolysis. Analytical Chemistry, 70, 2651.

56. Bernas, T., Rajwa, B. P., Asem, E. K., \& Robinson, J. P. (2005). Loss of image quality in photobleaching during microscopic imaging of fluorescent probes bound to chromatin. Journal of Biomedical Optics, 10, 064015

57. Bernas, T., Zarębski, M., Cook, R. R., \& Dobrucki, J. W. (2004). Minimizing photobleaching during confocal microscopy of fluorescent probes bound to chromatin: Role of anoxia and photon flux. Journal of Microscopy, 215, 281.

58. Drummond, D. R., Carter, N., \& Cross, R. A. (2002). An electronically tunable ultrafast laser source applied to fluorescence imaging and fluorescence lifetime imaging microscopy. Journal of Microscopy, 206, 161.

59. Patterson, G. H., \& Piston, D. W. (2000). Photobleaching in twophoton excitation microscopy. Biophysical Journal, 78, 2159.

60. Zhang, H., Salo, D., Kim, D. M., Komarov, S., Tai, Y., \& Berezin, M. Y. (2016). Penetration depth of photons in biological tissues from hyperspectral imaging in shortwave infrared in transmission and reflection geometries. Journal of Biomedical Optics, 21, 126006

61. Ash, C., Dubec, M., Donne, K., \& Bashford, T. (2017). Effect of wavelength and beam width on penetration in light-tissue interaction using computational methods. Lasers in Medical Science, $32,1909$.

62. He, G. S., Tan, L. S., Zheng, Q., \& Prasad, P. N. (2008). Multiphoton absorbing materials:? Molecular designs, characterizations, and applications. Chemical Reviews, 108, 1245.

63. Zipfel, W. R., Williams, R. M., \& Webb, W. W. (2003). Nonlinear magic: Multiphoton microscopy in the biosciences. Nature Biotechnology, 21, 1368.

64. Mikhaylov, A., de Reguardati, S., Pahapill, J., Callis, P. R., Kohler, B., \& Rebane, A. (2018). Two-photon absorption spectra of fluorescent isomorphic DNA base analogs. Biomedical Optics Express, 9, 447.

65. Katilius, E., \& Woodbury, N. W. (2006). Multiphoton excitation of fluorescent DNA base analogs. Journal of Biomedical Optics, 11,044004

66. Stanley, R. J., Hou, Z. J., Yang, A. P., \& Hawkins, M. E. (2005). The two-photon excitation cross section of 6MAP, a fluorescent adenine analogue. The Journal of Physical Chemistry B, 109, 3690.

67. Samaan, G. N., Wyllie, M. K., Cizmic, J. M., Needham, L., Nobis, D., Ngo, K., Andersen, S., Magennis, S. W., Lee, S. F., \& Purse, B. W. (2021). Single-molecule fluorescence detection of a tricyclic nucleoside analogue. Chemical Science, 12, 2623.

68. Fisher, R. S., Nobis, D., Füchtbauer, A. F., Bood, M., Grøtli, M., Wilhelmsson, L. M., Jones, A. C., \& Magennis, S. W. (2018). Pulse-shaped two-photon excitation of a fluorescent base analogue approaches single-molecule sensitivity. Physical Chemistry Chemical Physics, 20, 28487.

69. Frisch, M. J., Trucks, G. W., Schlegel, H. B., Scuseria, G. E., Robb, M. A., Cheeseman, J. R., Scalmani, G., Barone, V., 
Petersson, G. A., Nakatsuji, H., Li, X., Caricato, M., Marenich, A. V., Bloino, J., Janesko, B. G., Gomperts, R., Mennucci, B., Hratchian, H. P., Ortiz, J.V., \& Fox, D. J. (2009). Gaussian09. Wallingford CT: Gaussian Inc.

70. Dennington, R., Keith, T. A., \& Millam, J. M. (2009). Gaussview Version 5. Shawnee Mission KS: Semichem Inc.

71. Chai, J., \& Head-Gordon, M. (2008). Long-range corrected hybrid density functionals with damped atom-atom dispersion corrections. Physical Chemistry Chemical Physics, 10, 6615.

72. Huber, R. G., Margreiter, M. A., Fuchs, J. E., von Grafenstein, S., Tautermann, C. S., Liedl, K. R., \& Fox, T. (2014). Heteroaromatic pstacking energy landscapes. Journal of Chemical Information and Modeling, 54, 1371.

73. Kruszynski, R., \& Sierański, T. (2016). Can stacking interactions exist beyond the commonly accepted limits? Crystal Growth \& Design, 16, 587.

74. Sierański, T. (2016). Intricasies of the Stacking interaction in a Pyrrole-Pyrrole system. Structural Chemistry, 27, 1107.

75. Maiti, S., \& Bhattacharyya, D. (2017). Stacking interactions involving non-Watson-Crick BasePairs: Dispersion corrected density functional studies. Physical Chemistry Chemical Physics, 19, 28718.

76. Dunning, T. H. (1989). Gaussian basis sets for use in correlated molecular calculations. I. The atoms boron through neon and hydrogen. The Journal of Chemical Physics, 90.

77. Kendall, R. A., Dunning, T. H., \& Harrison, R. J. (1992). Electron affinities of the first-row atoms revisited. Systematic basis sets and wave functions. The Journal of Chemical Physics, 96.

78. Woon, D. E., \& Dunning, T. H. (1993). Gaussian basis sets for use in correlated molecular calculations. III. The atoms aluminum through argon. The Journal of Chemical Physics, 98.

79. Reibnegger, G. (2018). A DFT study on the one-electron reduction/oxidation of biologically relevant pteridine derivatives. ChemistrySelect, 3, 10925.

80. Jaramillo, P., Coutinho, K., \& Canuto, S. (2010). Electron invariants and excited state structural analysis for electronic transitions within CIS, RPA, and TDDFT models. International Journal of Quantum Chemistry, 110, 2371.

81. Reibnegger, G. (2015). An ab initio and density functional theory study on neutral pterin radicals. Pteridines, 26, 135.

82. Soniat, M., \& Martin, C. B. (2008). Theoretical study on the relative energies of neutral pterin tautomers. Pteridines, 19, 120.

83. Soniat, M., \& Martin, C. B. (2009). Theoretical Study on the Relative Energies of Anionic Pterin Tautomers. Pteridines, 20, 124.

84. Soniat, M., \& Martin, C. B. (2015). Binding affinities of folic acid and related pterins with biological macromolecules under physiological conditions. Pteridines, 26, 13.

85. Poater, J., Swart, M., Bickelhaupt, F. M., \& Guerra, C. F. (2014). B-DNA structure and stability: the role of hydrogen bonding, $\pi$ $-\pi$ stacking interactions, twist-angle, and solvation. Organic and Biomolecular Chemistry, 12, 4691.

86. Yakovchuk, P., Protozanova, E., \& Frank-Kamenetskii, M. D. (2006). Base-stacking and base-pairing contributions into thermal stability of the DNA double helix. Nucleic Acids Research, 34,564 .

87. Tomasi, J., Mennucci, B., \& Cammi, R. (2005). Quantum mechanical continuum solvation models. Chemical Reviews, 105, 2999.

88. Lipparini, F., Scalmani, G., Mennucci, B., Cances, E., Caricato, M., \& Frisch, M. J. (2010). A variational formulation of the polarizable continuum model. The Journal of Chemical Physics, 133, 014106.
89. Yanai, T., Tew, D. P., \& Handy, N. C. (2004). A new hybrid exchange-correlation functional using the Coulomb-attenuating method (CAM-B3LYP). Chemical Physics Letters, 393, 51.

90. Miehlich, B., Savin, A., Stoll, H., \& Preuss, H. (1989). Results obtained with the correlation energy density functionals of becke and Lee, Yang and Parr. Chemical Physics Letters, 157, 200.

91. Lee, C., Yang, W., \& Parr, R. G. (1988). Development of the Colle-Salvetti correlation-energy formula into a functional of the electron density. Physical Review, 37, 785.

92. Becke, A. D. (1993). A new mixing of Hartree"Fock and local density"functional theories. J. Chem. Phys., 98, 1372.

93. Becke, A. D. (1988). Density-functional exchange-energy approximation with correct asymptotic behavior. Phys. Rev., 38, 3098.

94. Krishnan, R., Binkley, J. S., Seeger, R., \& Pople, J. A. (1980). The Journal of Chemical Physics, 72, 650.

95. Lee, C., Yang, W., \& Parr, R. G. (1988). Physical Review B, 37, 785.

96. Becke, A. D. (1999). Density-functional exchange-energy approximation with correct asymptotic behavior. Physical Review A, 38, 3098.

97. Perdew, J. P. (1986). Density-functional approximation for the correlation energy of the inhomogeneous electron gas. Physical Review B, 33, 8822 .

98. Adamo, C., \& Barone, V. (1999). Toward reliable density functional methods without adjustable parameters: The PBE0 model. The Journal of Chemical Physics, 110, 6158.

99. Dunning, T.H. (1989) Gaussian basis sets for use in correlated molecular calculations. I. The atoms boron through neon and hydrogen. The Journal of Chemical Physics, 90, 1007

100. Sapunar, M., Domcke, W., \& Došlić, N. (2019). UV absorption spectra of DNA bases in the 350-190 nm range: Assignment and state specific analysis of solvation effects. Physical Chemistry Chemical Physics, 41, 22782.

101. Datta, K., Johnson, N. P., Villani, G., Marcus, A. H., \& von Hippel, P. H. (2012). Characterization of the 6-methyl isoxanthopterin (6-MI) base analog dimer, a spectroscopic probe for monitoring guanine base conformations at specific sites in nucleic acids. Nucleic Acids Research, 40, 1191.

102. Patersin, M. J., Christiansen, O., Pawłowski, F., Jørgensen, P., Hättig, C., Helgaker, T., \& Sałek, P. J. (2006). Benchmarking two-photon absorption with $\mathrm{CC} 3$ quadratic response theory, and comparison with density functional response theory. Chemical Physics, 124,, 22782.

103. Arnberg, J., Jiménez-Banzo, A., Patersin, M. J., Nonell, S., Borrell, J. I., Christiansen, O., \& Ogilby, P. R. (2007). Two-Photon Absorption in Tetraphenylporphycenes: Are Porphycenes Better Candidates Than Porphyrins for Providing Optimal Optical Properties for Two-Photon Photodynamic Therapy? Journal of the American Chemical Society, 129, 5188.

104. Bergendahl, L. T., \& Paterson, M. J. (2012). A two-photon absorption-molecular structure investigation using a porphycene chromophore with promising photodynamic therapy characteristics. The Journal of Physical Chemistry B, 116, 11818.

105. Graczyk, A., Žurek, J. M., \& Paterson, M. J. (2014). On the linear and non-linear electronic spectroscopy of chlorophylls: A computational study. Photochemical and Photobiological Sciences, 13, 103.

106. Arnberg, J., Paterson, M. J., Nielsen, C. B., Jørgensen, M., Christiansen, O., \& Ogilby, P. R. (2007). One- and two-photon photosensitized singlet oxygen production: Development and characterization of aromatic ketones as standard sensitizers. The Journal of Physical Chemistry A, 111, 5756.

107. Johnsen, M., Paterson, M. J., Arnberg, F., Christiansen, O., Nielsen, C. B., Jørgensen, M., \& Ogilby, P. R. (2008). Effects of 
conjugation length and resonance enhancement on two-photon absorption in phenylene-vinylene oligomers. Physical Chemistry Chemical Physics, 10, 1177.

108. Bergendahl, L. T., \& Paterson, M. J. (2012). Two-photon absorption in porphycenic macrocycles: The effect of tuning the core aromatic electronic structure. Chemical Communications, 48, 1544.

109. Aidas, K., Angeli, C., Bak, K. L., Bakken, V., Bast, R., Boman, L., Christiansen, O., Cimiraglia, R., Coriani, S., Dahle, P., Dalskov, E. K., Ekström, U., Enevoldsen, T., Eriksen, J. J., Ettenhuber, P., Fernádez, B., Ferrighi, L., Fliegl, H., Frediani, L., \& H. (2014). The Dalton Quantum Chemistry Program System. WIREs Computational Molecular Science, 4, 269.

110. Dalton, a molecular electronic structure program, release v 2020.0 (2020), see http://daltonprogram.org

111. Thellamurege, N. M., \& Li, H. (2012). Note: FixSol solvation model and FIXPVA2 tessellation scheme. The Journal of Chemical Physics, 137,, 246101.

112. Nørby, M. S., Steinmann, C., Olsen, J. M. H., Li, H., \& Kongsted, J. (2016). Computational approach for studying optical properties of DNA systems in solution. Journal of Chemical Theory and Computation, 12, 5050.

113. Beerepoot, M. T., Friese, D. H., List, N. H., Kongsted, J., \& Ruud, K. (2015). Benchmarking two-photon absorption cross sections: Performance of CC2 and CAM-B3LYP. Physical Chemistry Chemical Physics, 17, 19306.

114. Zhang, P., Chiu, C. K. C., Huang, H., Lam, Y. P. Y., Habtemariam, A., Malcomson, T., et al. (2017). Organoiridium photosensitizers can induce specific oxidative attack on proteins within cancer cells. Angewandte Chemie International Edition, 56, 14898.

115. Huang, H., Banerjee, S., Qiu, K., Blacque, O., Malcomson, T., Paterson, M. J., et al. (2019). Targeted photoredox catalysis in cancer cells. Nature Chemistry, 11, 1041.

116. Albota, M., Beljonne, D., Brédas, J., Ehrlich, J. E., Fu, J., Heikal, A. A., Hess, S. E., Kogej, T., Levin, M. D., Marder, S. R., McCord-Maughon, D., Perry, R. H., Joseph, W., Rumi, M., Subramaniam, G., Webb, W. W., Wu, X., \& Xu, C. (1998). Design of organic molecules with large two-photon absorption cross sections. Science, 281, 1653.
117. Beverina, L., Fu, J., Leclercq, A., Zojer, E., Pacher, P., Barlow, S., et al. (2005). Two-photon absorption at telecommunications wavelengths in a dipolar chromophore with a pyrrole auxiliary donor and thiazole auxiliary acceptor. Journal of the American Chemical Society, 127, 7282.

118. Zheng, S., Leclercq, A., Fu, J., Beverina, L., Padilha, L. A., Zojer, E., Schmidt, K., Barlow, S., Luo, J., Jiang, S., Jen, A. K., Yi, Y., Shuai, Z., Hagan, E. W. V. D. J., Brédas, J., \& Marder, S. R. (2007). Two-photon absorption in quadrupolar bis (acceptor)terminated chromophores with electron-rich bis (heterocycle) vinylene bridges. Chemistry of Materials, 19, 432.

119. Masunov, A., \& Tretiak, S. S. (2004). Prediction of two-photon absorption properties for organic chromophores using timedependent density-functional theory. The Journal of Physical Chemistry A, 108, 899.

120. Mourant, J. R., Frever, J., Hielscher, A., Fick, A., Shen, D., \& Johnson, T. (1998). Mechanisms of light scattering from biological cells relevant to noninvasive optical-tissue diagnostics. Applied Optics, 37, 3586.

121. Mourant, J. R., Canpolat, M., Brocker, C., Esponda-Ramos, O., Johnson, T., Matanock, A., Stetter, K., \& Freyer, J. (2000). Light scattering from cells: The contribution of the nucleus and the effects of proliferative status. Journal of Biomedical Optics, 5, 131.

122. Stolik, S., Delgado, J. A., Perez, A., \& Anasagasti, L. (2000). Measurement of the penetration depths of red and near infrared light in human "ex vivo" tissues. The Journal of Photochemistry and Photobiology B, 57, 90.

123. Meath, W. J. (2016). On the optimization, and the intensity dependence, of the excitation rate for the absorption of twophotons due to the direct permanent dipole moment excitation mechanism. AIP Advances, 6, 075202.

124. Drobizhev, M., Makarov, N. S., Rebane, A., de la Torre, G., \& Torres, T. (2008). Strong two-photon absorption in push pull phthalocyanines: Role of resonance enhancement and permanent dipole moment change upon excitation. The Journal of Physical Chemistry C, 112, 848 .

125. Jagatap, B. N., \& Meath, W. J. (2002). Contributions of permanent dipole moments to molecular multiphoton excitation cross sections. Journal of the Optical Society of America B, 19, 2673. 